\title{
Phyllomedusa: posição taxonômica, hábitos e biologia (Amphibia, Anura, Hylidae)
}

\author{
Ulisses Caramaschi e Carlos Alberto Gonçalves Cruz \\ Departamento de Vertebrados, Museu Nacional/UFRJ, Quinta da Boa Vista, 20940-040, Rio de Janeiro, RJ, Brasil. \\ E-mails: ulisses@acd.ufrj.br e cagcruz@uol.com.br \\ Bolsistas do Conselho Nacional de Desenvolvimento Científico e Tecnológico (CNPq).
}

\begin{abstract}
Phyllomedusa: taxonomic status, habits, and biology (Amphibia, Anura, Hylidae). Diagnosis for the Hylidae family of tree-frogs, and diagnosis and included genera for the four subfamilies currently in this family, Hemiphractinae, Hylinae, Pelodryadinae, and Phyllomedusinae, are provided. The genera of the Phyllomedusinae subfamily, Agalychnis, Hylomantis, Pachymedusa, Phasmahyla, Phrynomedusa, and Phyllome$d u s a$, are diagnosed and the species included and their geographical distribution are referred. Notes on the habits and biology of members of the genus Phyllomedusa are presented.
\end{abstract}

Keywords: Amphibia; Anura; Hylidae; Hemiphractinae; Hylinae; Pelodryadinae; Phyllomedusinae; Agalychnis; Hylomantis; Pachymedusa; Phasmahyla; Phrynomedusa; Phyllomedusa; taxonomy; biology.

Palavras-chave: Amphibia; Anura; Hylidae; Hemiphractinae; Hylinae; Pelodryadinae; Phyllomedusinae; Agalychnis; Hylomantis; Pachymedusa; Phasmahyla; Phrynomedusa; Phyllomedusa; taxonomia; biologia.

Os membros da grande e diversificada família Hylidae Rafinesque, 1815 (Amphibia: Anura) possuem cintura peitoral do tipo arcífero, com um esterno desenvolvido, oito vértebras pré-sacrais procélicas, diapófises sacrais pouco dilatadas, articulação da vértebra sacral com o uróstilo bicondilar, pré-maxilares e maxilares providos de odontóides, uma cartilagem intercalar entre a última e a penúltima falanges dos dígitos e amplexo axilar. A família inclui atualmente mais de 720 espécies, distribuídas pelas Américas do Norte, Central e do Sul, nas Índias Ocidentais e na Região Australo-Papuana; um grupo de espécies de Hyla penetra na Eurásia temperada, incluindo o extremo norte da África e o Arquipélago Japonês (Frost, 2000). Atual-

Recebido em 08.12.2001

Aceito em 02.01.2002 mente, está subdividida em quatro subfamílias, quais sejam:

Hemiphractinae Peters, 1862 - Ovos carregados no dorso da fêmea até a submetamorfose ou até a metamorfose, neste caso com liberação de jovens semelhantes aos adultos; pupila horizontal; odontóides maxilares e pré-vomerinos presentes; diapófises sacrais dilatadas ou cilíndricas; exostose craniana mais ou menos acentuada em algumas formas; músculo inter-hióideo não se estende além do final da mandíbula; músculo intermandibular com desenvolvimento variável de ramos acessórios. Inclui os gêneros Cryptobatrachus Ruthven, 1916, Flectonotus Miranda-Ribeiro, 1920, Gastrotheca Fitzinger, 1843, Hemiphractus Wagler, 1828 e Stefania Rivero, 1968 [1966].

Hylinae Gadow, 1901 - Ossificação craniana variável, comumente sem fusōes ósseas ex- 
tensivas; pele da cabeça usualmente nãocoossificada ao crânio, embora o seja nos grupos com cabeça ossificada ("casque-headed"); pupila horizontal; odontóides maxilares presentes e pré-maxilares geralmente presentes; falange terminal dos dígitos em forma de garra expandida na base, geralmente coberta por um disco dilatado; diapófises sacrais geralmente dilatadas; músculo inter-hióideo se estende posteriormente além do fínal da mandíbula; músculo intermandibular usualmente indiferenciado; larvas aquáticas, adultos terrestres, geralmente trepadores. Inclui os gêneros Acris Duméril e Bibron, 1841, Anotheca Smith, 1939, Aparasphenodon Miranda-Ribeiro, 1920, Aplastodiscus A. Lutz, 1950, Argenteohyla Trueb, 1970, Calyptahyla Trueb e Tyler, 1974, Corythomantis Boulenger, 1896, Duellmanohyla Campbell e Smith, 1992, Hyla Laurenti, 1768, Nyctimantis Boulenger, 1882, Osteocephalus Steindachner, 1862, Osteopilus Fitzinger, 1843, Phrynohyas Fitzinger, 1843, Phyllodytes Wagler, 1830, Plectrohyla Brocchi, 1877, Pseudacris Fitzinger, 1843, Pternohyla Boulenger, 1882, Ptychohyla Taylor, 1944, Scarthyla Duellman e De Sá, 1988, Scinax Wagler, 1830, Smilisca Cope, 1865, Sphaenorhynchus Tschudi, 1838, Tepuihyla Ayarzagüena, Señaris e Gorzula, 1993 [1992], Trachycephalus Tschudi, 1838, Triprion Cope, 1866 e Xenohyla Izeckson, 1998 [1996].

Pelodryadinae Günther, 1859 [1858] Ossificação craniana variável, comumente sem fusões ósseas; pele da cabeça não-coossificada; pupila horizontal (exceto em Nyctimystes, que possui pupila vertical); músculo inter-hióideo se estende posteriormente além do final da mandíbula; músculo intermandibular com um elemento apical separado; desovas e larvas aquáticas. Inclui os gêneros Cyclorana Steindachner, 1867, Litoria Tschudi, 1838 e Nyctimystes Stejneger, 1916.

Phyllomedusinae Günther, 1858 - Ossificação do crânio variável, geralmente sem fusões ósseas extensivas; pele da cabeça não-coossificada ao crânio; pupila vertical; músculo interhióideo se estende posteriormente além do final da mandíbula; músculo intermandibular com ramos laterais acessórios; desova geralmente fora da água, sobre a vegetação ou em folhas enrola- das; girinos aquáticos, com espiráculo ventral, apenas levemente sinistro; pés agarradores ou tendência a essa capacidade; cartilagens intercalares, tamanho dos discos e extensão das membranas interdigitais progressivamente reduzidas; torsão do pé, com oposição dos dedos gradualmente desenvolvida. Inclui os gêneros Agalychnis Cope, 1864, Hylomantis Peters, 1873 [1872], Pachymedusa Duellman, 1968, Phasmahyla Cruz, 1991 [1990], Phrynomedusa Miranda-Ribeiro, 1923 e Phyllomedusa Wagler, 1830.

Neste trabalho, será dada ênfase aos membros da subfamília Phyllomedusinae, com especial atenção ao gênero Phyllomedusa. As definições dos gêneros seguem Duellman (1968) e Cruz (1991 [1990]). A definição das espéciestipo dos gêneros e da distribuição geográfica seguem Frost (2000).

\section{Subfamília Phyllomedusinae Günther, 1858}

Esta subfamília constitui uma das linhagens filogenéticas mais distintas dentre os Hylidae neotropicais, principalmente pela sua pupila vertical (horizontal em todos os outros hilídeos, exceto em Nyctimystes, um gênero da PapuaNova Guiné), colorido dorsal sempre verde e geralmente com cores vivas nas partes ocultas, por depositarem seus ovos em uma massa gelatinosa sobre folhas ou em folhas enroladas acima da água (hábito também encontrado apenas em espécies das famílias Centrolenidae e Rhacophoridae e em algumas poucas espécies de Hyla) (Duellman, 1968) e, como notaram Cei (1963) e Cei e Erspamer (1966), também diferem notavelmente de todos os outros hilídeos neotropicais com base nas aminas e polipeptídeos da pele.

\section{Gênero Agalychnis Cope, 1864}

Espécie-tipo - Hyla callidryas Cope, 1864, por designação original.

Definição - Dedos e artelhos palmados pelo menos até a metade de seu comprimento; discos terminais grandes; primeiro artelho mais curto que o segundo e não-oponível aos outros; pele lisa, sem osteodermes; glândulas paratóides, se presentes, pobremente desenvolvidas e difusas; membrana palpebral reticulada (exceto em $A$. 
calcarifer); íris vermelha ou amarela; crânio baixo, com altura menor que $40 \%$ do comprimento; nasais grandes; fontanela frontoparietal grande; quadratojugais reduzidos; dentes prévomerinos presentes; girinos aquáticos, generalizados.

Distribuição geográfica - Sul do México, América Central, terras baixas da vertente do Oceano Pacífico da Colômbia e noroeste do Equador e Equador Amazônico.

Composição - Contém oito espécies, conforme relacionado no Apêndice I.

\section{Gênero Hylomantis Peters, 1873 [1872]}

Espécie-tipo - Hylomantis aspera Peters, 1873 [1872], por monotipia.

Definição - Dedos e artelhos com palmatura vestigial a ausente; discos terminais de tamanho moderado, lanceolados; primeiro artelho mais curto que o segundo e não-oponível aos outros; pele acentuadamente granulosa; glândulas paratóides ausentes; membrana palpebral nãoreticulada; íris creme; crânio moderadamente baixo, com altura de cerca de $43 \%$ do comprimento; nasais grandes; fontanela frontoparietal grande; quadratojugais ausentes; dentes prévomerinos ausentes; girinos desconhecidos, mas provavelmente aquáticos e generalizados.

Distribuição geográfica - Floresta Atlântica nos estados da Bahia e Pernambuco, Brasil.

Composição - Contém duas espécies, conforme relacionado no Apêndice I.

\section{Gênero Pachymedusa Duellman, 1968}

Espécie-tipo - Phyllomedusa dacnicolor Cope, 1864, por designação original.

Definição - Dedos e artelhos com membrana apenas basal e fímbrias laterais; discos terminais grandes; primeiro artelho mais curto que o segundo e não-oponível aos outros; pele lisa ou com filigranas, sem osteodermes; glândulas paratóides presentes, difusas; membrana palpebral reticulada; íris amarelo-dourada, com reticulações pretas; crânio alto, com altura maior que $50 \%$ do comprimento; nasais grandes; fontanela frontoparietal moderadamente grande; quadratojugais robustos; dentes pré-vomerinos presentes; girinos aquáticos, generalizados.
Distribuição geográfica - Vertentes do Oceano Pacífico e terras baixas, do sul de Sonora até o Istmo de Tehuantepec, México.

Composição - Contém uma espécie, conforme relacionado no Apêndice I.

\section{Gênero Phasmahyla Cruz, 1991 [1990]}

Espécie-tipo - Phyllomedusa guttata A. Lutz, 1924, por designação original.

Definição - Dedos e artelhos com palmatura vestigial ou ausente; discos terminais moderados; primeiro artelho mais curto que o segundo e não-oponível aos outros; pele moderadamente granulosa, sem osteodermes; glândulas paratóides ausentes, mas está presente um par de glândulas látero-dorsais; membrana palpebral nãoreticulada; íris creme; crânio moderadamente alto, com altura de cerca de $46 \%$ do comprimento; nasais grandes; fontanela frontoparietal grande; quadratojugais presentes, reduzidos; dentes pré-vomerinos ausentes; girinos aquáticos, especializados, com a boca em posição ânterodorsal e provida de uma prega dérmica expandida em forma de funil.

Distribuição geográfica - Região da Mata Atlântica, no sudeste e sul do Brasil, do leste de Minas Gerais e sul da Bahia até o leste do Paraná.

Composição - Contém quatro espécies, conforme relacionado no Apêndice I (Figura 1).

Gênero Phrynomedusa Miranda-Ribeiro, 1923

Espécie-tipo - Phrynomedusa fimbriata Miranda-Ribeiro, 1923, por designação subseqüente.

Definição - Dedos palmados até pelo menos 1/3 de seu comprimento e artelhos palmados até mais da metade de seu comprimento; discos terminais moderados a grandes; primeiro artelho mais curto que o segundo e não-oponível aos outros; pele finamente granulosa, quase lisa, sem osteodermes; glândulas paratóides ausentes; membrana palpebral não-reticulada; íris bicolor, sendo o terço superior dourado e o restante acinzentado; crânio moderadamente alto, com altura de cerca de $46 \%$ do comprimento; nasais grandes; fontanela frontoparietal grande; 
quadratojugais ausentes; dentes pré-vomerinos em pequeno número ou ausentes; girinos aquáticos, generalizados.

Distribuição geográfica - Sudeste do Brasil.

Composição - Contém cinco espécies, conforme relacionado no Apêndice I.

\section{Gênero Phyllomedusa Wagler, 1830}

Espécie-tipo - Rana bicolor Boddaert, 1772, por monotipia.

Definição - Dedos e artelhos com membranas grandemente reduzidas ou ausentes; discos terminais pequenos; primeiro artelho mais curto, igual ou mais longo que o segundo, oponível ou não aos outros; pele lisa ou rugosa, com ou sem osteodermes; glândulas paratóides presentes na maioria das espécies, usualmente distintas e elevadas; membrana palpebral não-reticulada; íris uniformemente branco-prateada a bronze, com reticulações pretas; crânio moderado a alto, com altura maior que $38 \%$ do comprimento; nasais moderadamente pequenos; fontanela frontoparietal presente, variável em tamanho; quadratojugais reduzidos $\mathrm{em}$ algumas espécies; dentes pré-vomerinos presentes ou ausentes.

Distribuição geográfica - Costa Rica, Panamá, vertentes do Oceano Pacífico da Colômbia e América do Sul a leste dos Andes, incluindo Trinidad, para o sul até o norte da Argentina.

Composição - Contém 29 espécies, conforme relacionado no Apêndice I.

Phyllomedusa, a rainha da folhagem

O gênero Phyllomedusa foi proposto por Wagler (1830) para abrigar uma espécie tratada muito anteriormente por Boddaert (1772) como Rana bicolor. O nome do gênero é derivado do Grego "phyllo", significando folha ou folhagem, e "medousa", significando rainha ou protetora, portanto "rainha da folhagem" ou "protetora da folhagem". Esse nome foi dado em alusão à cor verde do animal, bem como ao seu tamanho, já que inclui uma das maiores espécies de hilídeos e que hoje constitui a maior espécie da subfamília e do gênero.

Todas as espécies de Phyllomedusa são arborícolas e, embora tenham capacidade de sal- tar, em geral caminham lentamente sobre galhos e folhas em busca de alimento ou de locais de repouso. Durante esses deslocamentos, as cores vivas das partes normalmente ocultas quando em repouso são exibidas, possivelmente atuando como um mecanismo de defesa aposemático, aparentemente associado à pele desses animais, que é rica em polipeptídeos complexos (Duellman e Trueb, 1986), aparentemente tóxicos, irritantes e mesmo venenosos. Por exemplo, segundo Lescure et al. (1995), algumas tribos indígenas amazônicas utilizam a secreção da pele de Phyllomedusa bicolor e de P. tarsius em várias práticas. Os Tícunas a usam na preparação do curare. Um índio Wayapi, da Guiana Francesa, relatou que os homens colocam essa secreção em escarificações feitas nos braços e acrescentou que isso tem o efeito de dar força para puxar o arco, assim como provoca uma diminuição da sensação de cãibras. As tribos do tronco lingüístico "pano" (Mayorunas, Marubos, Amahuacas e Matses) das margens do rio Javari, na região da fronteira entre Brasil e Peru, passam a secreção, misturada com saliva, em queimaduras recentes feitas nos braços e no peito. Isso provoca uma profunda indisposição inicial, seguida de um período de apatia de duas ou três horas e depois de um estado de euforia acompanhado de uma sensação de força e maior acuidade dos sentidos, o que os tornaria melhores caçadores e até mesmo aumentaria a chance de encontrar a caça. Um peptídeo, extraído dessa secreção e chamada de adenoregulina por Daly et al. (1992), produz esse efeito. Além disso, peptídeos vasodilatadores e opióides (dermofinas, dermencefalinas e deltorfinas) e antimicrobianos (dermaseptinas) foram isolados da secreção cutânea de $P$. bicolor (Amiche et al., 1994; Mor et al., 1994).

Quando tocadas ou apanhadas com a mão, algumas espécies de Phyllomedusa encolhem-se e ficam imóveis, em tanatose (p. ex., P. rohdei, Sazima, 1974; P. burmeisteri, Haddad e Sazima, 1992 - Figura 2), um comportamento defensivo conhecido e eficaz em casos de predação por certas serpentes, como Liophis miliaris (Sazima, 1974).

Quanto à regulação hídrica, conforme referido por Stebbins e Cohen (1995) e Zug et al. (2001), diversas espécies (p. ex., P. 


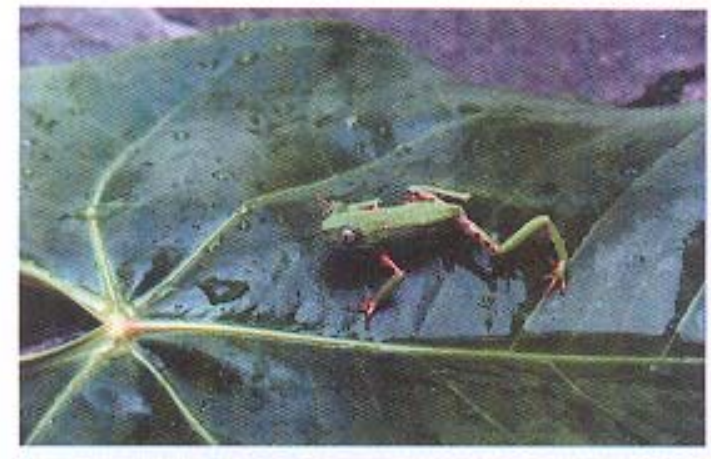

Figura 1 - Macho de Phasmahyia jandaia da Serra do Carą̧a (MG).

hypochondrialis e $P$. sauvagii) são uricotélicas, tendo desenvolvido a habilidade de excretar ácido úrico ao invés de uréia, como a maioria dos anfíbios, como mecanismo de retenção de água. $\mathrm{O}$ ácido úrico é um composto pouco solúvel, menos tóxico, que é precipitado e eliminado enquanto muito da água expelida no processo é reabsorvida no trato urinário. Nesse aspecto, esses anuros se assemelham mais aos répteis e às aves que aos outros anfíbios. Entretanto, o uricotelismo seria de pequena vantagem para as espécies de Phyllomedusa se a água fosse livremente perdida de outras maneiras, como por evaporação pela pele, por exemplo. Assim, aparentemente a maioria das espécies parece ter uma secreçäo cutânea lipídica que permite reduzir a perda de água. Em $P$. sauvagii, o mecanismo de retenção hídrica envolve: (1) seleção de um ramo apropriado para se empoleirar: (2) secreçāo da substância lipídica (primariamente ésteres graxos) sobre a superfície da pele através de numerosas e pequenas glândulas tegumentares; (3) utilização dos membros anteriores e posteriores em movimentos contorcionistas para espalhar e esfregar a secreção pelo corpo e selar a pele contra a perda de água; (4) torpor durante os períodos de atividade diurna; (5) atividade noturna. Esses anuros são capazes de sentir quando a impermeabilidade da pele é rompida e entāo fazem as apropriadas secreção e esfrega. Isso feito, a pele assume uma aparência seca e brilhante, e a taxa de perda de água diminui rapidamente. Por outro lado, anfíbios uricotélicos



Figura 2. Tanatose em um indivíduo de Pfillonedusa bumeisteri da Serra do Caraça (MG).

possuem altas taxas de absorção de água pela superfície ventral, de forma que podem repor rapidamente os níveis de água do corpo quando esta fica disponivel. Phyllomedusa sauvagii não somente absorve água dessa maneira, mas também bebe água de chuva que molha sua cabeça ou que goteja de folhas. $O$ animal volta sua cabeça para cima e faz vigorosos movimentos de bombeamento gular para engolir a água (McClanahan e Shoemaker, 1987).

A desova de Phyllomedusa ocorre tipicamente sobre folhas e ramos pendentes sobre a água. Enquanto em amplexo com um macho, a fêmea seleciona um local de desova e deposita de 100 a 150 ovos, que são fertilizados pelo macho. A fêmea e o macho, ainda $\mathrm{em}$ amplexo. descem até a água para que a fêmea possa absorvê-la antes de retornar ao local de desova original para depositar mais ovos. Essa sequência pode se repetir várias vezes até que se complete a desova, que é entāo abandonada pelo casal (Zug et al., 2001). Os embriōes se desenvolvem fora da água até a eclosão, quando, pela dissoluçāo das cápsulas gelatinosas e pelo próprio movimento das larvas, as folhas se abrem e os girinos caem na água, onde continuam seu desenvolvimento normalmente até a metamorfose.

Phyllomedusa, a rainha da folhagem, o gênero de hilídeos mais diferenciados e especializados, de colorido belo e característico, que se movem lenta e elegantemente e constróem ninhos para seus ovos, é o nome apropriado para esta nova publicação. 


\section{Referências Bibliográficas}

Amiche, M., F. Ducancel, A. Mor, J. C. Boulain, A. Menez e P. Nicolas. 1994. Precursors of vertebrate peptide antibiotics dermaseptine $b$ and adenoregulin have extensive sequence identities with precursors of opioid peptides dermophin, dermenkephalin, and deltorphins. Journal of Biological Chemistry 269: 17847-17852.

Boddaert, P, 1772. Over den Twee-koleurigen Kikvorsch. De Rana Bicolore, 41 pp., pls.

Cei, J. M. 1963. Some precipitin tests and preliminary remarks on the systematic relationships of four South American families of frogs. Bulletin of Serological Museum 30: 4-6.

Cei, J. M. e V. Erspamer. 1966. Biochemical taxonomy of South American amphibians by means of skin amines and polypeptides. Copeia 1966: 74-78.

Cruz, C. A. G. 1991 [1990]. Sobre as relações intergenéricas de Phyllomedusinae da Floresta Atlântica (Amphibia, Anura, Hylidae). Revista Brasileira de Biologia 50: $709-726$

Daly, J. W., J. Caceres, R. W. Moni, F. Gusovski, M. Moos, Jr., K. B. Seamon, K. Milton e C. H. Myers. 1992. Frog secretions and hunting magic in the upper Amazon: identification of a peptide that interacts with an adenosine receptor. National Academy of Sciences USA 89: 10960-10963.

Duellman, W. E. 1968. The genera of Phyllomedusinae frogs (Anura: Hylidae). University of Kansas Publications, Museum of Natural History 18: 1-10.

Duellman, W. E. e L. Trueb. 1986. Biology of Amphibians. New York, McGraw-Hill Book. Co. xvii +670 pp.

Frost, D. R. (Ed.), 2000. Amphibian Species of the World: An Online Reference. <http://research.amnh.org/ herpetology/amphibia/index.html> [capturado em 20.X1.2001].

Haddad, C. F. B. e I. Sazima. 1992. Anfíbios anuros da Serra do Japi. Pp. 188-211 In: Morellato, L. P. C (Org.). História Natural da Serra do Japi. Ecologia e Preservação de uma Área Florestal no Sudeste do Brasil. Campinas, Editora da UNICAMP/FAPESP.

Lescure, J., V. Marty, C. Marty, F. Starace, M. AuberThomay e F, Letellier. 1995. Contribution à l'étude des Amphibiens de Guyane française. X. Les Phyllomedusa (Anura, Hylidae). Revue Française d'Aquariologie et Herpétologie 22: 35-50.

McClanahan, Jr., L. L. e V. H. Shoemaker, 1987. Behavior and thermal relations of the arboreal frog Phyllomedusa sauvagei. National Geographic Research 3: 11-21.

Mor, A., M. Amiche e P. Nicolas. 1994. Structure, synthesis, and activity of dermaseptine b, a novel vertebrate defensive peptide from frog skin relationship with adenoregulin. Biochemistry 33 ; $6642-6650$.

Sazima, 1. 1974. Experimental predation on the leaf-frog Phyllomedusa rohdei by the water snake Liophis miliaris. Journal of Herpetology 8:376-377.

Stebbins, R. C. e N. W. Cohen. 1995. A Natural History of Amphibians. Princeton. Princeton University Press. $\mathrm{xvi}+316 \mathrm{pp}$.

Wagler, J. G. 1830. Näturliches System der Amphibien, mit vorangehender Classification der Saügethiere und Vögel. München, vi +354 pp., 9 pls.

Zug, G. R., L. J. Vitt e J. P. Caldwell. 2001. Herpetology An Introductory Biology of Amphibians and Reptiles. London. Academic Press. 2. Ed, xiv+630 pp.

Apêndice I

Lista das espécies da subfamília Phyllomedusinae

Agalychnis annae (Duellman, 1963)

A. calcarifer Boulenger, 1902

A. callidryas (Cope, 1862)

A. craspedopus (Funkhouser, 1957)

A. litodryas (Duellman \& Trueb, 1967)

A. moreletii (Duméril, 1853)

A. saltator Taylor, 1955

A. spurrelli Boulenger, 1913

Hylomantis aspera Peters, 1873 [1872]

H. granulosa (Cruz, 1988)

Pachymedusa dacnicolor (Cope, 1864)

Phasmahyla cochranae (Bokermann, 1966)

P. exilis (Cruz, 1980)

P. guttata (A. Lutz, 1924)

P. jandaia (Bokermann \& Sazima, 1978)

Phrynomedusa appendiculata (A. Lutz, 1925)

P. bokermanni Cruz, 1991

P. fimbriata Miranda-Ribeiro, 1923

P. marginasa (Izecksohn \& Cruz, 1976)

P. vanzolinii Cruz, 1991

Phyllomedusa atelopoides Duellman, Cadle \& Cannatella, 1988

P. ayeaye (B. Lutz, 1966)

P. baltea Duellman \& Toft, 1979

P. bicolor (Boddaert, 1772)
$P$. boliviana Boulenger, 1902

P. buckleyi Boulenger, 1882

P. burmeisteri Boulenger, 1882

P. centralis Bokermann, 1965

P. coelestis (Cope, 1874)

P. danieli Ruiz-C., Hernandez-C. \& Rueda-A., 1988

P. distincta B. Lutz, 1950

P. duellmani Cannatella, 1982

P. ecuatoriana Cannatelta, 1982

P. hulli Duellman \& Mendelson, 1995

P. hypochondrialis (Daudin, 1800)

$P$. iheringii Boulenger, 1885

$P$. lemur Boulenger, 1882

$P$. medinai Funkhouser, 1962

P. palliata Peters, 1873 [1872]

P. perinesos Duellman, 1973

P. psilopygion Cannatella, 1980

P. rohdei Mertens, 1926

P. sauvagii Boulenger, 1882

P. tarsius (Cope, 1868)

P. tetraploidea Pombal \& Haddad, 1992

P. tomopterna (Cope, 1868)

P. trinitatis Mertens, 1926

P. vaillantii Boulenger, 1882

P. venusta Duellman \& Trueb, 1967 